\title{
Grade Schoolers REACT Well to Visiting Scientists
}

Three years ago, after taking a job at EG\&G as a staff scientist, I met a fellow scientist named Nate Skinner. Nate had been doing chemistry demonstrations in local schools for 17 years, and I saw a chance to get into the classroom by accompanying an experienced presentor. I was terrified on my first classroom visit. Here we were in a class of fourth graders, and I realized that my $\mathrm{PhD}$ in chemistry was no match for a simple question like "Why does the water get hot when you add the powder?" (It was $\mathrm{CaCl}_{2}$.) A description of "exothermic reaction" driven by the laws of "thermodynamics" would be about as comprehensible as an answer given in Sanskrit. Also, knowing the "true" explanation for a reaction has nothing to do with how well the experiment goes in a classroom. (Nothing beats practice, practice, practice.)

After my fear of embarrassment subsided, we found that two scientists in the classroom worked better than one. We each played off the other's bad jokes, while keeping up the pace of our presentations. As Nate set up the next experiment, I filled the time asking questions and doing the equivalent of adding local color to a sports broadcast. Nate coached me in the presentation of the experiments, and I coached him on how well the kids understood what he was doing. I sometimes felt like a translator; words we commonly use in science are a foreign language to children, especially youth-at-risk children who typically have never known a scientist or engineer.

There had always been a high demand for Nate's demonstrations. Teachers usually heard about him through recommendations from other teachers. Teachers were now constantly inviting us into their classrooms. We saw that if two could reach some classes, a whole group of people might reach lots of kids, so REACTS (Rediscovery Educational Activities Create Tomorrow's Scientists) was born. REACTS has a mailing list of about 350 people, with about forty members who donate their time. REACTS is made up of parents, teachers, school administrators, scientists, and engineers. Last year, members of REACTS made presentations to approximately 4,000 children with chemistry and physics activities through "science days," classroom and club demonstrations, and public events like Earth Day. A core of about six demonstrators did most of the presentations, with Nate present for the lion's share. We have learned quite a bit from teachers and parents, and of course from the children. Of the many possible pitfalls, we have probably stepped in most of them, and have been able to incorporate about half the excellent suggestions we received.

Here are some recommendations. Don't wait until you think it is a perfect presentation or idea-get involved and then work out the details. Ask teachers what they need and tell them what you are willing to do. Elementary teachers must cover a large amount of required material, so they have little time left to learn to do new scientific demonstrations themselves. We use two formats for classroom or after-school club presentations: the demonstrations and the round-robin hands-on activity. The first is a "whiz-bang" demonstration where the children help us perform each experiment. The round robin is made up of five or six hands-on stations (tables) monitored by two adults. In the latter format the children rotate among tables, eight minutes for each stop. We discovered the "seven-second rule" always applies in any format: If you

\section{Sample experiments:}

Chemical reactions: Put baking soda in a balloon. Put the balloon on top of a bottle with vinegar in it and a small neck. Allow the baking soda to fall into the vinegar. Watch the $\mathrm{CO} 2$ evolve and blow up the balloon. Why does the mixture get cold?

Acids and bases: Dilute $\mathrm{HCl}$ and dilute $\mathrm{NaOH}$. Use crushed roses, cabbage juice, tumeric, or other plants as a $\mathrm{pH}$ indicator.

Momentum and friction: Set up a bottle with paper underneath. Pull the paper out at different speeds. At which speeds does the bottle move with the paper, and at which speeds does it remain in place?

Some sources for experiments that make good demonstrations:

GEMS-Great Explorations in Math and Science, Lawrence Hall of Science, University of California at Berkeley, Berkeley, CA 94720; (415) 642-7771.

AIMS-Activities that Integrate Math and Science, AIMS Educational Foundation, P.O. Box 7766, Fresno, CA 93747; (209) 255-4094.

175 Experiments to Amaze and Amuse Your Friends, by Brenda Walpole, Random House. turn your back for seven seconds without giving the class some task like a hands-on experiment, you will loose the attention of about half the children. Do that a few times and the teacher should pull out the big hook and tow you outside.

The key to the success of any presentation is always preparation. Our experiments are designed to work well and have been tested thoroughly. (I still carry notes with me and ask the students to help me interpret them.) In science, we know that many of our greatest discoveries have been found in the flasks of "failed" experiments. The key is to let children know that science is unpredictable, but without performing uncontrolled experiments in the classroom. An experiment that always "fails" when you do it is a perfect start. One example we use is an addition of water and dish soap to dry baking soda and sodium bisulfate. The neutralization produces more foam than the tall thin glass can hold, and a mess results. We always emphasize prior to the mixing that we have carefully measured the solid proportions so that the foam stops right at the top.

Make sure that the material is on a level that the students will understand and enjoy. You may want several versions of an experiment for different age groups, and several explanations using concepts they know. Have the teacher or parents involved ask you questions just like they are children in the class. It will encourage others to ask questions and give you an idea of how you are being heard. Remember-you are not there to provide answers. Focus on the questions and do not be afraid to say "I don't know." As scientists, we are too accustomed to turning up the technical vocabulary with lay people whenever we are unsure of our answers. Children have a great filter for this-they simply stop listening.

When you need help, the key for an organization like REACTS is having people do what they know how to do, and training them to do the rest. For example, the treasurer on the board of directors is an accountant. But also, the woman responsible for scheduling demonstrations is now learning how to perform them. We have spent a great deal of time training people to do experiments in chemistry and physics. Physics is easier to do in a hands-on format, as it does not require set-up or cleanup time, and there is no accurate weighing required. Chemistry can be a bit less predictable (chaos $=$ fun).

REACTS is made up entirely of people who have full-time jobs, so often it takes 
longer to get things done than one would hope. REACTS affiliated with the California Cooperative Extension and it became a 4-H Club. Richard Penzio, at the Cooperative extension at UC-Davis, helped us articulate what we had seen: kids are really turned on by hands-on activities. Penzio also warned us to avoid the "Sputnik Effect." In the 1960s, many dedicated scientists rode out into the schools to "save" our children from an education gap. Many activities were successful, but many scientists and engineers were unprepared for the experience. They often talked right over the heads of students and teachers alike. The gap between those who knew science and those who didn't only widened. While many scientists were excellent at including students as "junior scientists," we propagated the myth that there is something about science which makes it an exclusive club, understood only by the "Shell Answer Man" and "Dr. Science." (No offense, fellas.)
We also need to emphasize that scientists are not men in white lab coats carrying boiling beakers. Future women and minority scientists need role models in their classrooms that reflect the true make-up of the future work force. This time around there is a great deal of emphasis on having children discover that they are inquisitive by nature and very good at observing their world. We may accomplish that task best by providing them with training in inquiry learning and team problem solving as opposed to textbook memorization. Chaos theory tells us that small differences in the initial starting conditions can create dramatically different solutions. So go out and make a difference.

\section{JOHN DI BENEDETTO}

John Di Benedetto is a research scientist at EGEG in Santa Barbara, California. His cur rent research includes laser induced fluorescence and remote sensing. He is an executive director of REACTS along with Nate Skinner, a research scientist at XSIRIUS in Santa Barbara. REACTS is a part of the Santa Barbara 4-H Club Cooperative Extension. They can be reached at REACTS, P.O. Box 2374, Goleta, CA 93118. REACTS was featured last year in PARADE Magazine (April 14, 1991).

The Education Exchange highlights the experiences of scientists and engineers with local schools, along with helpful hints and resources. If you would like to share your own involvement in science education, contact Finley Shapiro, Department of Electrical and Computer Engineering, Drexel University, Philadelphia, PA 19104 U.S.A.; telephone (215) 895-6749; Fax (215) 895-1695; Email: shapiro@ece.drexel.edu

To receive additional information on how you can get involved in enhancing K-12 science education, circle number 120 on the Reader Service Card.

\section{Encyclopedia of Applied Physics}

\section{Edited by George L. Trigg}

The 20-volume Encyclopedia of Applied Physics is the first work of its kind to approach physics from the standpoint of technical and industrial applications.

Alphabetical coverage ensures that all aspects of applied physics are covered in depth. They include measurement science, the electronic, magnetic, dielectric, and optical properties of condensed matter, materials science, atomic and molecular physics, nuclear and elementary particle physics, biophysics, geophysics, space physics..

Sponsored by the American Institute of Physics, the German Physical Society, the Japanese Society of Applied Physics and the Physical Society of Japan.

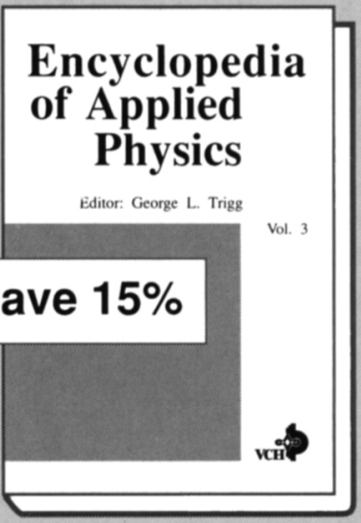

Subscription price: $\$ 250.00$ pervolume. Subscription period expires March 31 , 1993 after which the price per volume will be $\$ 295.00$. The Encyclopedia can be purchased only as a complete set.

\section{Subscri
00 pervolume
res March 31
ce per volum
complete set.}

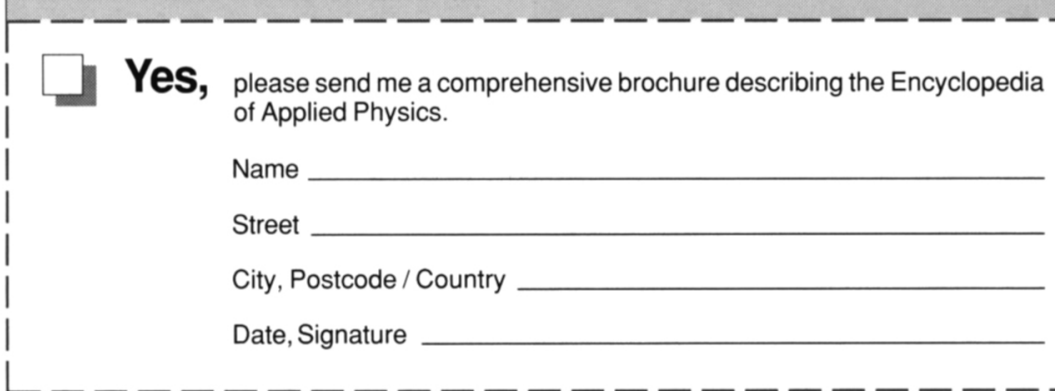

